\title{
Effect of Laser Power on Mechanical and Microstructure Properties of Pulsed Nd:YAG Laser Welded Dissimilar DP600- DP1000 Steel Sheets
}

\author{
Oğuz Tunçel ${ }^{*}(\mathbb{D}$, Hakan Aydın (D), Şükriye Çetin (1) \\ Engineering Faculty, Mechanical Engineering Department, Bursa Uludag University, 16059, Gorukle-Bursa
}

\begin{abstract}
In the present study, dissimilar dual-phase (DP) steel sheets (DP600-DP1000) were double-sided welded with Nd:YAG (Neodymium-doped Yttrium Aluminum Garnet (Y3Al5O12)) laser device and the effect of laser power on mechanical and microstructural properties of welded sheets was investigated. Laser welds were conducted using SISMA SWA300 Nd:YAG laser welding machine in the flat position with the butt joint. DP600 and DP1000 steels with a $1 \mathrm{~mm}$ thickness were selected for the experiments. Laser power was changed from $20 \%$ to $75 \%$, and other welding parameters were kept constant. To evaluate the welded samples, tensile, microhardness and optical microscope tests were performed. As a result of the study, in high laser power values, good quality welds were obtained. In microstructural studies, it was observed that three different regions were formed in the weld section; fusion zone (FZ), heat affected zone (HAZ) and base material (BM). These three regions were composed of different phase structures; FZ: martensite, bainite and retained austenite, HAZ: martensite, bainite, ferrite, retained austenite and tempered martensite, BM: ferrite and martensite. Also, different hardness values were measured in these different regions, particularly in the FZ highest microhardness values were measured due to effective martensite formation.
\end{abstract}

Keywords: Pulsed Nd:YAG laser welding, DP600 steel, DP1000 steel, laser power, mechanical properties, microstructure

\section{INTRODUCTION}

Advanced high strength steels (AHSS) procure higher elongation and formability for equal strength levels compared to conventional carbon steels and high strength low alloy (HSLA) steel groups. The automobile structures made from these steels have greater energy absorption capacity thanks to the combination of higher strength and better formability. And, this combination provides better crashworthiness[1]. DP steels are the most common used AHSS in the automotive industry for structural applications. The advantages of DP steels are high strength-to-weight ratio, low yield-to-ultimate strength ratio combined with a high initial work hardening rate and good formability. The combination of this steels includes soft ferrite matrix and hard martensite phase. And, sometimes DP steels can include ferrite and cementite with bainitic morphology as well [2].

The welding process is inevitable when joining the automobile parts. Especially, joining with laser welding has gained popularity against other joining techniques such as resis- tance spot welding (RSW) and friction stir welding (FSW) because of ease of automation, flexibility, high power density, small heat affected zone (HAZ), high weld bead depth-to-width ratio and small distortion[3]. Also, in the automotive industry the demand for dissimilar welding of steel sheets increases day by day due to reducing material cost and improve the car design. However, different physical and chemical properties of dissimilar steels between the welding counterparts and the possible formation of brittle intermetallic phases arise problems. Considering these problems, Nd:YAG laser welding has several advantages over other welding methods and laser sources because of controlling laser parameters precisely[4].

There are some researches studied on the Nd:YAG laser welding of DP steels in the literature which constitutes the basis of this study. Hazretinezhad et al. [5] studied the effect of energy input pattern in Nd:YAG laser welding of a $0.19 \%$ carbon DP steel on mechanical and metallurgical characteristics. In the results of experimental studies, they showed that the energy input pattern to the fusion zone had a signi-
* Corresponding authour

Email: otuncel@uludag.edu.tr
European Mechanical Science, March 2020, 4(1): 41-46 doi: https://doi.org/10.26701/ems.632173

Received: October 11, 2019

Accepted: November 19, 2019 
ficant effect on the ultimate tensile strength of welded samples. And, all samples were fractured from the HAZ. Xue et al. [6] investigated the influence of process parameters on weld penetration of the fusion zone during the pulsed Nd:YAG laser welding of DP steel butt joint. Their results showed that sufficient weld penetration was obtained between 40\%-60\% laser power and below the $40 \%$ laser power weld penetration had a sharp decrease. Seang et al. [7] aimed to determine the effect of Nd:YAG laser welding parameters on the hardness of the DP600 lap joint. Their study had an experimental and numerical approach. As a result of their study, they showed that the laser parameters were more effective on weld depth than weld width.

This article aims to investigate the effect of laser power on tensile properties, hardness profile and microstructure properties during double-sided Nd:YAG laser welding of dissimilar DP steels with butt joint.

\section{MATERIALS AND METHOD}

Commercial DP600 and DP1000 steel sheets typically used in the automotive industry were used for experimental studies. The chemical composition and the mechanical properties of the DP steels used in this study were given respectively in Tab. 1 and Tab. 2, respectively.

Table 1. Chemical Properties of DP600 and DP1000

\begin{tabular}{|c|c|c|c|c|c|}
\hline Steel & C & Mn & Si & Cu+Cr+Ni & Cr \\
\hline DP600 & 0.12 & 1.40 & 0.5 & 1.3 & - \\
\hline DP1000 & 0.16 & 1.89 & 0.26 & - & 0.44 \\
\hline
\end{tabular}

Table 2. Mechanical Properties of DP600 and DP1000

\begin{tabular}{|c|c|c|c|}
\hline & Yield Strength & Tensile Strength & Elongation \\
\hline Steel & $\mathrm{MPa}$ & $\mathrm{MPa}$ & $\%$ \\
\hline DP600 & 370 & 630 & 24 \\
\hline DP1000 & 660 & 1020 & 13.5 \\
\hline
\end{tabular}

Before the welding operations, the samples were cut into pieces in a dimension of $100 \times 260 \mathrm{~mm}$. The rolling direction was considered while cutting and the rolling direction was determined parallel to the transverse edge. A SISMA SWA 300 pulsed Nd:YAG laser welding machine with a maximum $300 \mathrm{~W}$ mean power was used for performing the welding operations. And, a special fixture was made to guarantee full contact between the weld samples surfaces (Fig. 1).

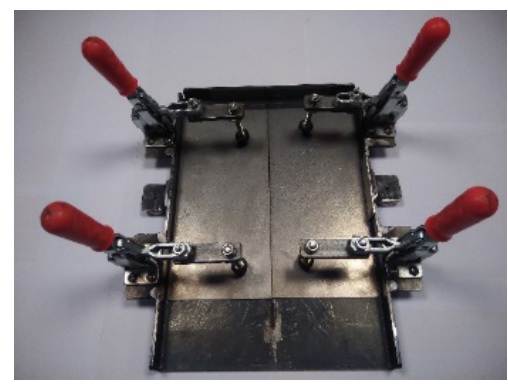

Figure 1. The fixture used in the welding operations

Weld operations were performed in the flat position with butt joint without adding filler material. During welding operations, argon shielding gas was employed. The focal length from the sheet surface was $120 \mathrm{~mm}$. All welds were conducted perpendicular to the rolling direction (Fig. 2a). This study aimed to determine the effect of laser power on mechanical and microstructure properties of the welded samples. To accomplish this purpose, laser power changed from $20 \%$ to $75 \%$ and other welding parameters were kept constant: pulse duration $5 \mathrm{~ms}$, pulse frequency $5 \mathrm{hz}$, focal spot diameter $1.4 \mathrm{~mm}$ and welding speed $4 \mathrm{~mm} / \mathrm{s}$ (Tab. 3).

Table 3. Welding parameters used in this study

\begin{tabular}{|c|c|c|c|c|}
\hline $\begin{array}{c}\text { Laser Power } \\
\text { Percent }\end{array}$ & $\begin{array}{c}\text { Pulse Dura- } \\
\text { tion Time }\end{array}$ & Pulse Frequency & $\begin{array}{c}\text { Focal Spot } \\
\text { Diameter }\end{array}$ & $\begin{array}{c}\text { Welding } \\
\text { Speed }\end{array}$ \\
\hline$\%$ & $\mathrm{~ms}$ & $\mathrm{~Hz}$ & $\mathrm{~mm}$ & $\mathrm{~mm} / \mathrm{s}$ \\
\hline 20 & 5 & 5 & 1.4 & 4 \\
\hline 35 & 5 & 5 & 1.4 & 4 \\
\hline 50 & 5 & 5 & 1.4 & 4 \\
\hline 65 & 5 & 5 & 1.4 & 4 \\
\hline 75 & 5 & 5 & 1.4 & 4 \\
\hline
\end{tabular}

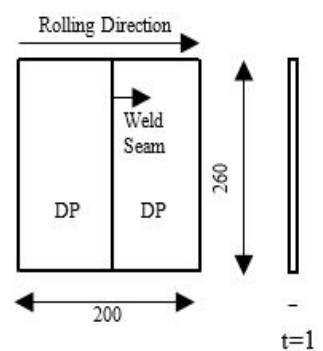

a)

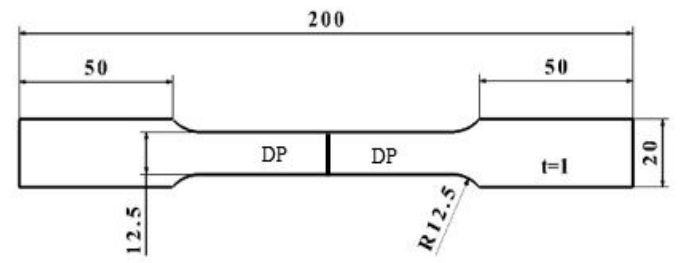

b)

Figure 2. a) Schematic illustration of laser welded DP steel sheets; b) Dimensions of the tensile test specimens [8]

The tensile test samples were established according to ASTM E8/E8M [8] (Fig. 2b). The computerized UTEST-7014 uniaxial tensile testing machine was used for evaluating the tensile test properties of welded samples. Tensile tests were performed with a constant crosshead displacement speed of $5 \mathrm{~mm} / \mathrm{min}$ at room temperature. After welding operations, the specimens for microstructure and microhardness studies specimens were cut from the weld cross-section, ground and polished. Then, these specimens were etched with 3\% nital reagent for 10-15 seconds. The hardness of specimens was measured across the weld zone using a Duroline-M microhardness tester with a 100-gram load during a holding time of 10 seconds.

\section{RESULTS \& DISCUSSION}

In experimental studies, the samples were welded with different laser power percents $(20 \%, 35 \%, 50 \%, 65 \%$, and $75 \%)$ to determine the effect of laser power on mechanical and microstructure properties. Weld quality was experimentally 
determined using the tensile tests. Tensile test results were given in Tab.4.

Table 4.Tensile strength and elongation of the laser welded joints (average values)

\begin{tabular}{ccc}
\hline $\begin{array}{c}\text { Laser Power } \\
\text { Percent }\end{array}$ & $\begin{array}{c}\text { Tensile } \\
\text { Strength }\end{array}$ & Elongation \\
\hline$\%$ & $\mathrm{MPa}$ & $\%$ \\
\hline 20 & 204.25 & 1.7 \\
35 & 258 & 2.08 \\
50 & 401.67 & 6.3 \\
65 & 586.5 & 15.46 \\
75 & 610.8 & 19.44 \\
\hline
\end{tabular}

The tensile test results showed that laser power significantly affected the tensile strength and elongation values. Tensile strength of the double-sided laser welded dissimilar DP600DP1000 joints significantly increased with increasing laser power (Fig.3). The tensile strength $(610.8 \mathrm{MPa})$ in the joint welded with laser power of $75 \%$ was almost equal to that of DP600 base metal (Tab. 2 and Tab. 4). According to these tensile test results, it can be said that successful welds could be accomplished through higher laser powers (65\%, 75\%). The effect of laser power on elongation can be seen in Fig. 4. Similar to tensile strength, highest elongation values were obtained with $65 \%$ and $75 \%$ laser powers. The highest elongation value was $20.45 \%$ at $75 \%$ laser power, and this value can be quite satisfactory for modern automotive industrial applications.

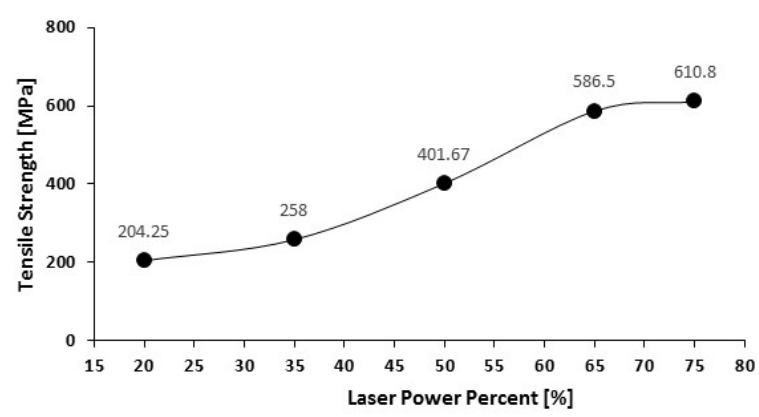

Figure 3. Tensile strength of Nd:YAG laser welded dissimilar DP600DP1000 steel sheets joints versus laser power percent [\%]

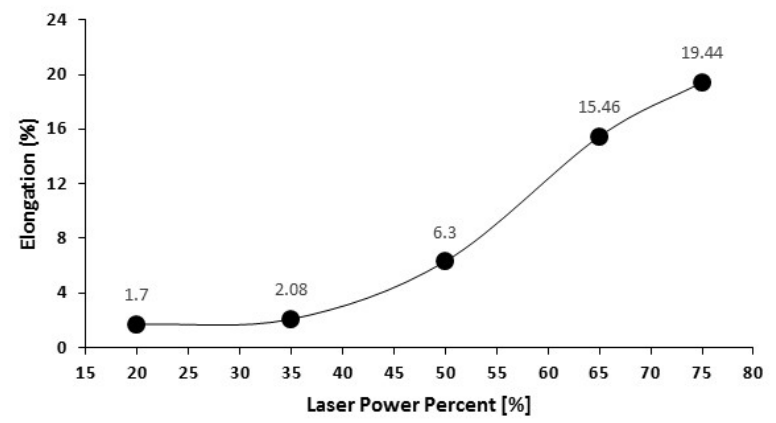

Figure 4. Elongation of Nd:YAG laser welded dissimilar DP600-DP1000 steel sheet joints versus laser power percent [\%].

Fig. 5 and Fig. 6 show the microhardness measurements results from the weld cross-section of the samples produ- ced with 20\% laser power and $75 \%$ laser power, respectively. Microhardness measurements were performed along the weld cross-section on a line with $100 \mu \mathrm{m}$ intervals. Along this line, distinct hardness regions were observed for three different zones; fusion zone (FZ), heat affected zone (HAZ) and base material (BM). For low and high laser powers, the highest microhardness values were obtained in the FZ. The highest microhardness values in the FZ were measured between $400-415 \mathrm{Hv}_{0.1}$. The reason for high hardness values in FZ was the effective martensite formation. HAZ widths of the welded samples were quite narrow with nearly 300$400 \mu \mathrm{m}$. Especially, pretty sharp microhardness decreases were observed on HAZ of DP 600 side. This hardness drop in HAZ can be associated with a small amount of ferrite,

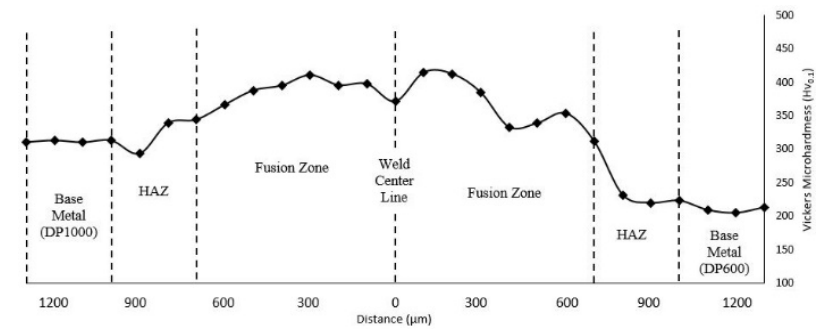

Figure 5. Hardness variation of the weld zone in the sample produced with laser power percent of $20 \%$

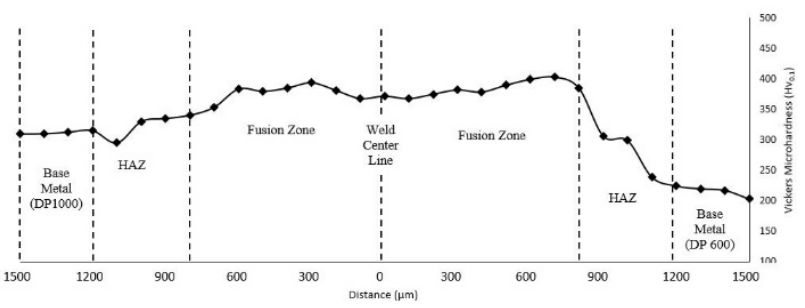

Figure 6. Hardness variation of the weld zone in the sample produced with laser power percent of $75 \%$

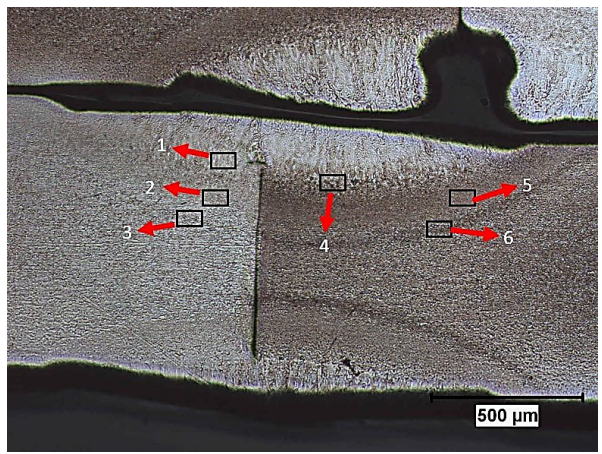

a)

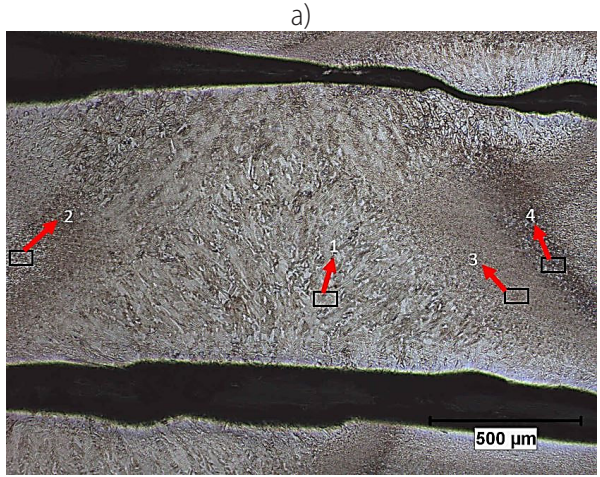

b)

Figure 7. Macro images of the welded samples with a) $20 \%$ laser power percent, b) $75 \%$ laser power percent 
bainite and essentially tempered martensite between the FZ and BM. Furthermore, on the DP1000 side tempering of the BM in a narrow zone between the HAZ and BM caused significantly softening with the formation of ferrite and iron carbide. In this small zone, the hardness was measured approximately $295 \mathrm{Hv}_{0.1}$ and this value was lower than that of the DP1000 BM.

Fig. 7 shows the weld cross sections of Nd:YAG laser welded dissimilar DP600-DP1000 joints with different laser power percents. In the weld cross-section three main distinct zones were observed; FZ, HAZ, and BM. Higher laser power resulted in deeper penetration and larger FZ size due to the higher heat input. Full X-shaped joined zone can be seen only Fig. $7 \mathrm{~b}$ with laser power of $75 \%$. On the other hand, the unbonded section was observed in Fig. 7a due to lack of heat input.

Magnified images of marked regions for $20 \%$ laser power joint in Fig.7a were shown in Fig. 8. In Fig. 7a, $1^{\text {st }}, 2^{\text {nd }}, 3^{\text {rd }}, 4^{\text {th }}$, $5^{\text {th }}$, and $6^{\text {th }}$ regions show FZ, HAZ on DP600 side, the intersection of HAZ and BM on DP600 side, the intersection of FZ and HAZ on DP 1000 side, HAZ on DP1000 side and the intersection of HAZ and BM on DP1000 side, respectively. In the $1^{\text {st }}$ region, $\mathrm{FZ}$ consists of almost completely martensite phase (Fig. 8a). In this zone, melting was achieved in a small area as a result of intensive heat input and then as a result of rapid cooling which is characteristic of laser welding, martensite was formed and a small amount of bainite and some retained austenite may occur. The $2^{\text {nd }}$ region is HAZ on the DP600 side and composed of bainite and tempered martensite (Fig 8b). The $3^{\text {rd }}$ region is the intersection of HAZ and $\mathrm{BM}$ on the DP600 side, and this region has mainly BM microstructural properties (Fig. 8c). However, close to HAZ, the tempered martensite and bainite are observed. The $4^{\text {th }}$ region (intersection of FZ and HAZ on DP1000 side) consists of martensite, bainite and tempered martensite (Fig. 8d). The $5^{\text {th }}$ region (HAZ on DP1000 side) consists of tempered martensite, retained austenite and bainite mixture (Fig. 8e). The $6^{\text {th }}$ region was softened zone in the intersection of HAZ and BM on DP1000 side, which contains tempered martensite, bainite, ferrite and iron carbides (Fig.8f).

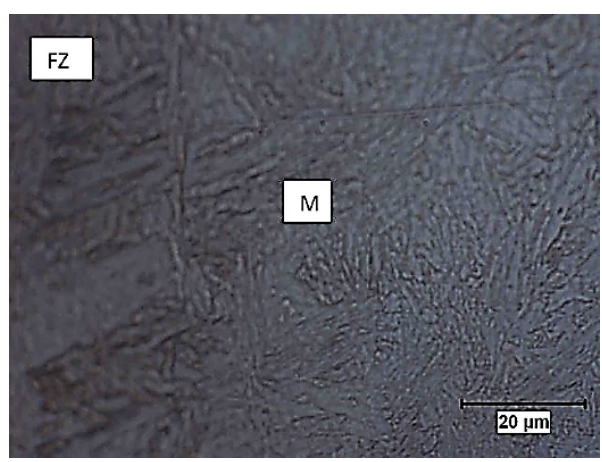

a)

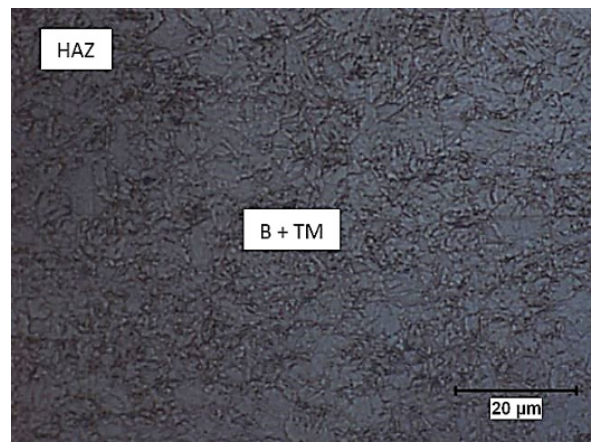

b)
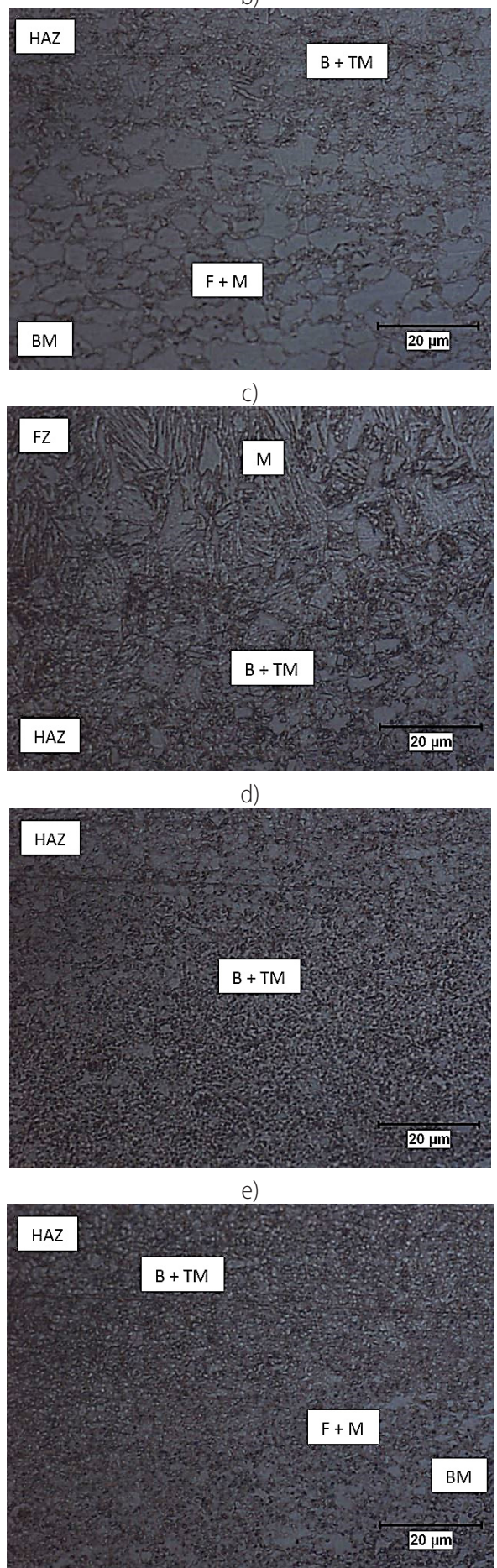

Figure 8. The microstructures of Nd:YAG laser welded DP600-DP1000 joints with $20 \%$ laser power percent a) FZ b) HAZ on DP600 side c) Intersection of HAZ and BM on DP600 side d) Intersection of FZ and HAZ on DP1000 side e) HAZ on DP1000 side $f$ ) Intersection of HAZ and BM on DP1000 side (F:Ferrite, M:Martensite, B:Bainite, TM:Tempered Martensite) 


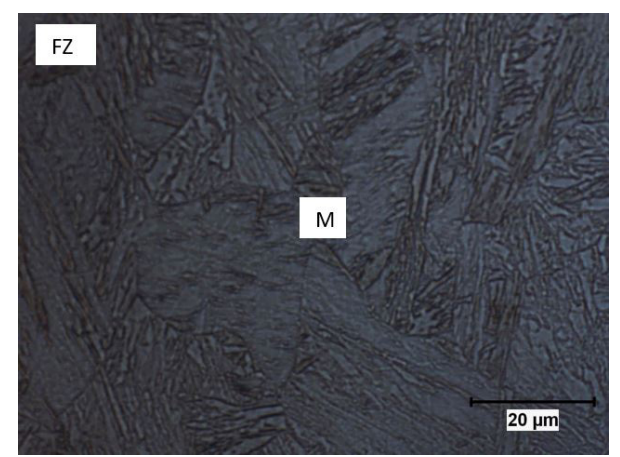

a)

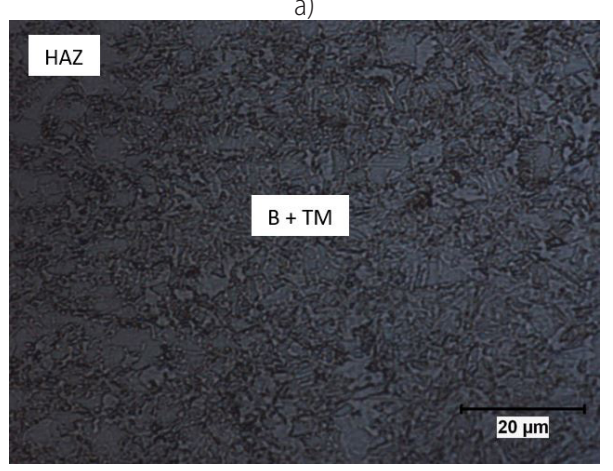

b)

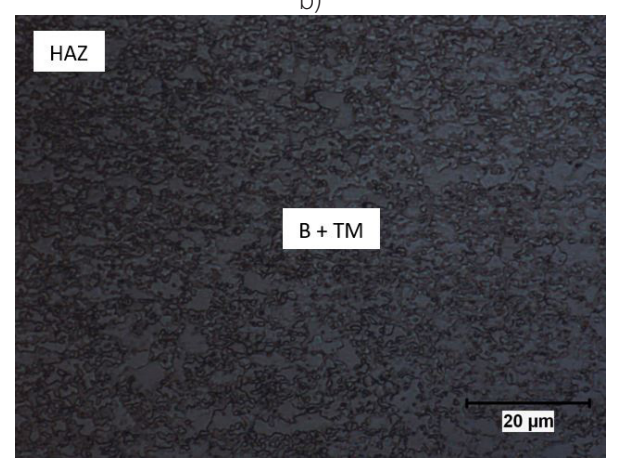

c)

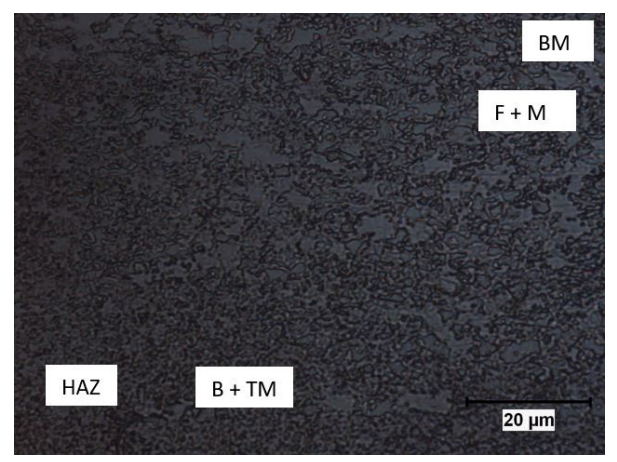

d)

Figure 9. The microstructures of Nd:YAG laser welded DP600-DP1000 joints a) FZ b) HAZ on DP600 side c) HAZ on DP600 side d) Intersection of HAZ and BM on DP1000 side (F:Ferrite, M:Martensite, B:Bainite, TM:Tempered Martensite)

Magnified images of marked regions for $75 \%$ laser power joint in Fig.7b were shown in Fig. 9. In Fig. $7 b, 1^{\text {st }}, 2^{\text {nd }}, 3^{\text {rd }}$, and $4^{\text {th }}$ regions show FZ, HAZ on DP600 side, HAZ on DP1000 side and intersection of HAZ and BM on DP1000 side, respectively. In the $1^{\text {st }}$ region martensite was formed completely and it is thought there may be a little amount of retained austenite (Fig.9a). $2^{\text {nd }}$ region and $3^{\text {rd }}$ region are HAZ on the DP600 side and DP1000 side respectively. These zones con- sist of bainite and tempered martensite (Fig.8b, Fig.8c). The $4^{\text {th }}$ region is softened zone in the intersection of HAZ and BM on DP1000 side, which contains tempered martensite, bainite, ferrite and iron carbides (Fig.8d).

\section{CONCLUSIONS}

In this study, the effect of laser power on microstructure and mechanical properties of dissimilar DP600-DP1000 steel sheets double-sided welded with Nd:YAG laser device were investigated. And, the following conclusions can be drawn:

- The increase of laser power from $20 \%$ to $75 \%$ improved the tensile strength from 204.25 $\mathrm{MPa}$ to $610.8 \mathrm{MPa}$. And, good quality welds were performed with high power rate because of high penetration through higher high heat input.

- $20 \%$ of laser power was inadequate with the constant laser parameters used in the study. The welds made in this parameter had a large gap in the weld center due to the lack of penetration.

- The elongation values were measured $15 \%-20 \%$ at $65 \%$ $75 \%$ laser power, and these values were very pretty satisfactory for the modern automotive industrial applications.

- In the weld zone, the hard martensite phase was formed as a result of the melting in a narrow area. The hardness of the fusion zone was two times higher than the hardness of DP600 BM.

- As a result of tempering, a characteristic softened zone occurred in between HAZ and DP1000 BM.

- The reason for the lower hardness in HAZ compared to $\mathrm{FZ}$ was the formation of bainite and tempered martensite in this region.

\section{ACKNOWLEDGMENT}

This study is supported by the Scientific Research Fund (BAP) of Uludag University (Project Contract No. $\operatorname{HDP}(\mathrm{MH})-2017 / 47)$.

\section{REFERENCES}

[1] Chadbeigi, H., Pinna, C., Celotto, S., Yates, J.R., (2010). Local plastic strain evolution in a high strength dual-phase steel. Materials Science and Engineering A 527(18-19): 5026-32, Doi: 10.1016/j. msea.2010.04.052.

[2] Ghassemi-Armaki, H., Maaß, R., Bhat, S.P., Sriram, S., Greer, J.R., Kumar, K.S., (2014). Deformation response of ferrite and martensite in a dual-phase steel. Acta Materialia 62(1): 197-211, Doi: 10.1016/j. actamat.2013.10.001.

[3] Dong, D., Liu, Y., Yang, Y., Li, J., Ma, M., Jiang, T., (2014). Microstructure and dynamic tensile behavior of DP600 dual phase steel joint by laser welding. Materials Science and Engineering A 594: 17-25, Doi: 10.1016/j.msea.2013.11.047.

[4] Torkamany, M.J., Malek Ghaini, F., Poursalehi, R., (2014). Dissimilar pulsed Nd: YAG laser welding of pure niobium to Ti-6Al-4V. Materials and Design 53: 915-20, Doi: 10.1016/j.matdes.2013.07.094. 
[5] Hazratinezhad, M., Mostafa Arab, N.B., Sufizadeh, A.R., Torkamany, M.J., (2012). Mechanical and metallurgical properties of pulsed neodymium-doped yttrium aluminum garnet laser welding of dual phase steels. Materials and Design 33(1): 83-7, Doi: 10.1016/j.matdes.2011.06.070.

[6] Xue, X., Pereira, A., Amorim, J., Liao, J., (2017). Effects of Pulsed Nd:YAG Laser Welding Parameters on Penetration and Microstructure Characterization of a DP1000 Steel Butt Joint. Metals 7(8): 292, Doi: 10.3390/met7080292.

[7] Seang, C., David, A.K., Ragneau, E., (2013). Effect of Nd:YAG laser welding parameters on the hardness of lap joint: Experimental and numerical approach. Physics Procedia 41: 38-40, Doi: 10.1016/j. phpro.2013.03.049.

[8] ASTM E8/E8M Standard Test Methods for Tension Testing of Metallic Materials, (2009) 